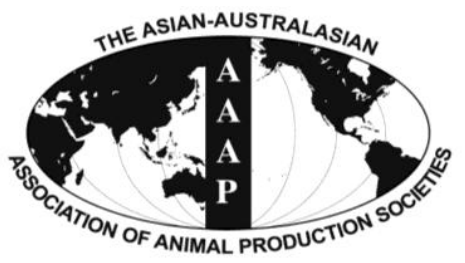

Asian-Aust. J. Anim. Sci.

Vol. 25, No. 11 : 1507-1510 November 2012

http://dx.doi.org/10.5713/ajas.2012.12116

www.ajas.info

pISSN 1011-2367 elSSN 1976-5517

\title{
Detection of Quantitative Trait Loci Affecting Fat Deposition Traits in Pigs
}

\author{
B. H. Choi, K. T. Lee, H. J. Lee, G. W. Jang, H. Y. Lee, B. W. Cho ${ }^{1}$, J. Y. Han ${ }^{2}$ and T. H. Kim* \\ National Institute of Animal Science, RDA, Suwon, Kyeonggi 441-706, Korea
}

\begin{abstract}
Quantitative trait loci (QTL) associated with fat deposition traits in pigs are important gene positions in a chromosome that influence meat quality of pork. For QTL study, a three generation resource population was constructed from a cross between Korean native boars and Landrace sows. A total of 240 F2 animals from intercross of F1 were produced. 80 microsatellite markers covering chromosomes 1 to 10 were selected to genotype the resource population. Intervals between adjacent markers were approximately $19 \mathrm{cM}$. Linkage analysis was performed using CRIMAP software version 2.4 with a FIXED option to obtain the map distances. For QTL analysis, the public web-based software, QTL express (http://www.qtl.cap.ed.ac.uk) was used. Two significant and two suggestive QTL were identified on SSC 6, 7, and 8 as affecting body fat and IMF traits. For QTL affecting IMF, the most significant association was detected between marker sw71 and $s w 1881$ on SSC 6, and a suggestive QTL was identified between $s w 268$ and $s w 205$ on SSC8. These QTL accounted for $26.58 \%$ and $12.31 \%$ of the phenotypic variance, respectively. A significant QTL affecting IMF was detected at position $105 \mathrm{cM}$ between markers sw71 and sw1881 on SSC 6. (Key Words: Quantitative Trait Loci, Pig, Intramuscular Fat, Body Fat, Microsatellite Marker)
\end{abstract}

\section{INTRODUCTION}

Quantitative trait loci (QTL) are gene positions in a chromosome that influence multifactorial traits that are determined by several genes as well as environmental factors and the interactions between them. Comprehensive genetic maps of the porcine genome have been developed during the last decade (Marklund et al., 1996; Rohrer et al., 1996). These genetic maps can be used to search for individual loci affecting economically important traits. Andersson et al. (1994) identified QTL for fat deposition traits in pigs on SSC 4 via a genome-wide scan. Several other QTL for fat deposition traits have subsequently been reported (Knott et al., 1998; Paszek et al., 1999; Rohrer, 2000). Recently, Grindflek et al. (2001) identified a QTL affecting intramuscular fat (IMF) content on SSC 6, which was supported by additional studies (De Koning et al., 1999; Ovilo et al., 2000). Here we mapped QTL for fat traits in pigs using interval mapping on chromosomes 1 to

\footnotetext{
* Corresponding Author: T. H. Kim. Tel: +82-31-290-1603, Fax:+82-31-290-1602, E-mail: thkim63@korea.kr

${ }^{1}$ Pusan National University, Miryang 627-706, Gyeongnam, Korea.

${ }^{2}$ Seoul National University, Seoul 151-742, Korea.

Submitted Mar. 3, 2012; Accepted Apr. 20, 2012; Revised May 11, 2012
}

10 using a Korean native pig $\times$ Landrace resource family constructed from a cross between the two phenotypically divergent swine breeds.

\section{MATERIALS AND METHODS}

The resource population was developed by a cross between Korean native boars and Landrace sows. Specifically, five boars of the Korean native pig and 10 sows of Landrace were selected randomly from a herd at the National Livestock Research Institute, Rural Development Administration, Korea. Each boar was mated naturally with two different sows to produce $F_{1}$ animals. An F1 sire was selected randomly from each litter and mated naturally with all sows of the same litter. Thus, 10 sires and 36 dams overall were used to produce $240 \mathrm{~F}_{2}$ animals.

After slaughtering, the body fat, comprising abdominal fat and fat trimmed from cut meat, was weighed. The intramuscular fat content (IMF) was determined from a sample of longissimus muscle using the CEM technique.

Blood samples were collected from all $\mathrm{F}_{2}$ animals and their parents $\left(\mathrm{F}_{1}\right)$ and grandparents $\left(\mathrm{F}_{0}\right)$, and DNA was isolated using the Wizzard Genomic DNA Purification Kit (Promega, Madison, WI, USA).

Markers were selected based on ease of scoring, 
informativeness, and location in the genome. In total, 80 markers covering chromosomes 1 to 10 were selected to genotype the resource population. Intervals between adjacent markers were less than $20 \mathrm{cM}$ whenever possible, and the average marker interval was approximately $19 \mathrm{cM}$ based on the USDA-MARC map (Rohrer et al., 1996). Microsatellite markers were amplified by PCR using $10 \mathrm{ng}$ pig genomic DNA as a template. PCR was performed in 10 $\mu l$ reactions with $10 \mathrm{mM}$ Tris- $\mathrm{HCl}(\mathrm{pH} 8.3), 50 \mathrm{mM} \mathrm{KCl}$, $1.5 \mathrm{mM} \mathrm{MgCl}_{2}, 200 \mathrm{uM}$ each dNTP, 3 pmole each primer, 0.5 units Taq DNA polymerase (TaKaRa Shuzo Co., Shiga, Japan). Thermal cycling conditions included an initial denaturation for $5 \mathrm{~min}$ at $94^{\circ} \mathrm{C}$, followed by 35 cycles of 30 $\mathrm{s}$ at $94^{\circ} \mathrm{C}$ for denaturation, $30 \mathrm{~s}$ at optimum temperature depends on markers for annealing and $1 \mathrm{~min}$ at $72^{\circ} \mathrm{C}$ for extension, and a final extension of $10 \mathrm{~min}$ at $72^{\circ} \mathrm{C}$ in GeneAmp PCR System 9600 (Perkin-Elmer Co., USA). The fragment lengths of the PCR products were determined with Genescan software version 2.1 (Perkin-Elmer Co., USA), and marker genotypes were assigned to the animals using Genotyper software version 2.5 (Perkin-Elmer Co., USA).

Linkage analysis was performed using CRIMAP software version 2.4 (Green et al., 1990) with a FIXED option to obtain the map distances. The maps were then used for QTL analysis of the 10 autosomes, which was conducted using the interval mapping procedure with the least squares regression method under the outbred line cross concept, in which founder breeds or lines are assumed to be fitted for alternative alleles at the QTL affecting the traits of interest. The statistical model included sex and slaughter data as fixed effects and live weight as coverable. A single QTL was fitted in all cases by regression on additive and dominance coefficients for the QTL at each $1 \mathrm{cM}$ putative position. Additive and dominance coefficients at a given position of the QTL were derived from marker data using the procedure of Haley et al. (1994).

\section{RESULTS AND DISCUSSION}

QTL affecting fat deposition traits were analyzed using a three-generation resource population constructed between Korean native boars and Landrace sows in Table 1. The QTL detected at a minimum chromosome-wide level of 5\%
Table 1. Means and phenotypic standard deviations of fat traits

\begin{tabular}{lccc}
\hline Trait & $\begin{array}{c}\text { Number } \\
\text { of pigs }\end{array}$ & Mean & $\begin{array}{c}\text { Standard } \\
\text { deviation }\end{array}$ \\
\hline Backfat thickness $(\mathrm{mm})$ & 240 & 21.62 & 8.08 \\
Total body fat content $(\mathrm{kg})$ & 240 & 10.13 & 5.24 \\
Intramuscular fat content $(\%)$ & 240 & 2.47 & 3.08 \\
\hline
\end{tabular}

are listed in Table 2. Two significant and two suggestive QTL were identified on $S S C$ 6, 7, and 8 as affecting body fat and IMF traits in Figure 1, 2, 3 and 4. For QTL affecting IMF, the most significant association was detected between marker sw71 and sw1881 on SSC 6, and a suggestive QTL was identified between $s w 268$ and $s w 205$ on SSC8. These QTL accounted for $26.58 \%$ and $12.31 \%$ of the phenotypic variance, respectively. The former QTL was significant at a $1 \%$ chromosome-wide level. The Korean native pig alleles were responsible for the higher intramuscular fat content. Additionally, a significant and a suggestive QTL for body fat were identified on SSC 7 and SSC 6. For the QTL on $S S C$ 7, Korean native pig alleles were associated with higher body fat. The QTL for body fat on SSC 6, however, was positively affected by the alleles of Landrace pigs, which were detected between the same markers that identified QTL for IMF. These QTL accounted for $18.38 \%$ and $12.87 \%$ of the phenotypic variance, respectively.

A significant QTL affecting IMF was detected at position $105 \mathrm{cM}$ between markers $s w 71$ and $s w 1881$ on

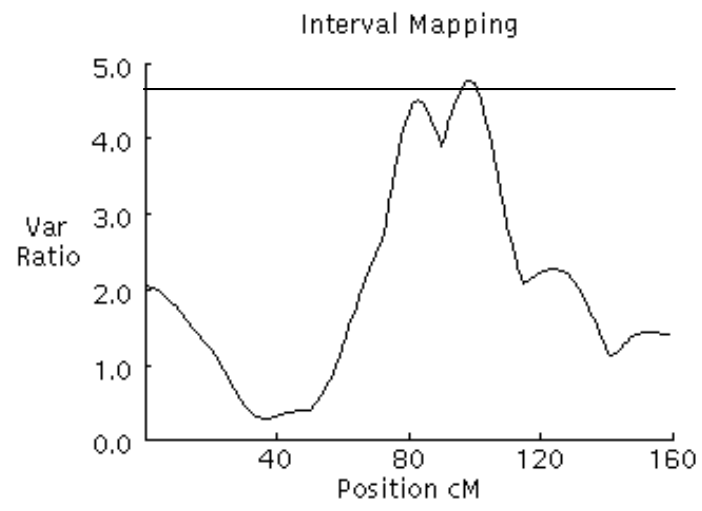

Figure 1. F-ratio curves for body fat on chromosome 6. The $x$-axis indicates the relative position on the linkage map. The $y$-axis represents the F-ratio. The horizontal line indicates the $5 \%$ chromosome-wide significance level from the permutation test.

Table 2. Chromosome-wide significance and suggestive associations of chromosomal regions with fat deposition traits

\begin{tabular}{|c|c|c|c|c|c|c|c|c|}
\hline \multirow{2}{*}{$\mathrm{SSC}$} & \multirow{2}{*}{ Trait } & \multirow{2}{*}{ Loc. (cM) } & \multirow{2}{*}{$\mathrm{F}$} & \multicolumn{2}{|c|}{ Additive } & \multicolumn{2}{|c|}{ Dominance } & \multirow{2}{*}{$\operatorname{var} \%$} \\
\hline & & & & Estimate & SE & Estimate & SE & \\
\hline 6 & Body fat ${ }^{\mathrm{a}}$ & 98 & 4.78 & -1.498 & 0.726 & 2.811 & 1.119 & 12.87 \\
\hline 6 & $\mathrm{IMF}^{\mathrm{b}}$ & 105 & 9.34 & 1.513 & 0.455 & -2.329 & 0.705 & 26.58 \\
\hline 7 & Body fat & 23 & 8.30 & 1.860 & 0.525 & -3.282 & 1.065 & 18.38 \\
\hline 8 & IMF & 38 & 5.84 & 1.225 & 0.474 & -1.300 & 0.819 & 12.31 \\
\hline
\end{tabular}

${ }^{\mathrm{a}}$ Body fat, including abdominal and trimmed fat from cut meat. ${ }^{\mathrm{b}}$ Intramuscular fat content. 


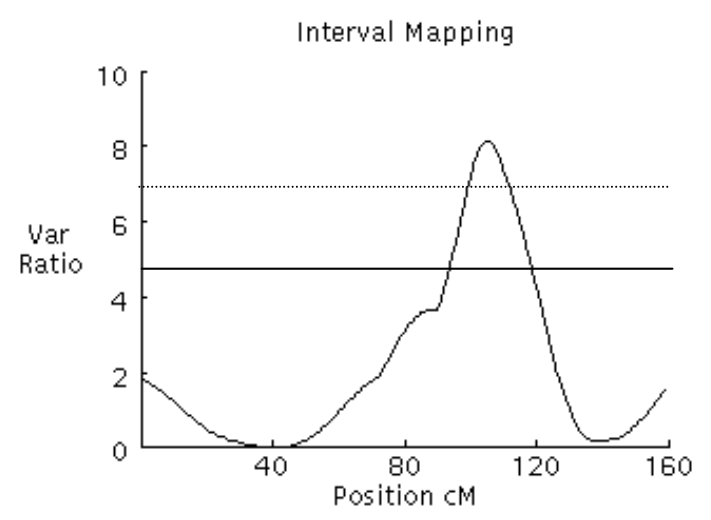

Figure 2. F-ratio curves for intramuscular fat on chromosome 6. The $\mathrm{x}$-axis indicates the relative position on the linkage map. The y-axis represents the F-ratio. The two lines represent the 5\% chromosome-wide (-) and $1 \%$ chromosome-wide ( $\cdots)$ significance levels from the permutation test.

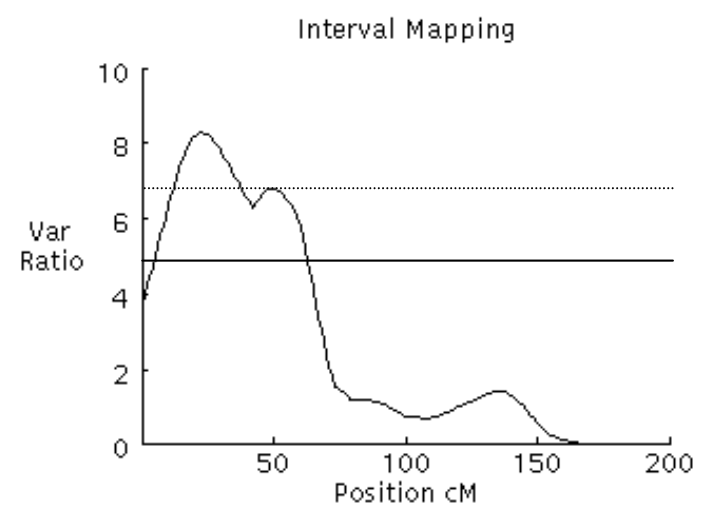

Figure 3. F-ratio curves for body fat on chromosome 7. The x-axis indicates the relative position on the linkage map. The y-axis represents the F-ratio. The two lines indicate the 5\% chromosomewide (-) and $1 \%$ chromosome-wide ( $\cdots$ ) significance level from the permutation test.

SSC 6. This QTL is well supported by previous reports in the literatures (De Koning et al., 1999; Ovilo et al., 2000; Grindflek et al., 2001). Ovilo et al. (2000) reported that a highly significant QTL affecting IMF and back fat thickness was located between 97 and $98 \mathrm{cM}$ on SSC6, which is close to the marker $s w 1881$. Similarly, a QTL affecting IMF was located between markers $s w 1823$ and s0003 (Grindfleck et al., 2001), and marker $s 0003$ and sw2419 (De Koning et al., 1999) on SSC 6. Finally, a genetic variant of the porcine heart fatty acid binding protein (HFABP) was associated with IMF in Duroc pigs (Gerbens et al., 1999), which was mapped to marker interval sw316-s0003 (Gerbens et al., 2000). The marker $s 0003$ was located between $s w 71$ and sw1881 genotyped in the present study. Therefore, the marker intervals for the QTL affecting IMF are almost identical between the present results and previous reports (De Koning et al., 1999; Ovilo et al., 2000; Grindflek et al., 2001). Additionally, Grindflek et al. (2001) suggested that

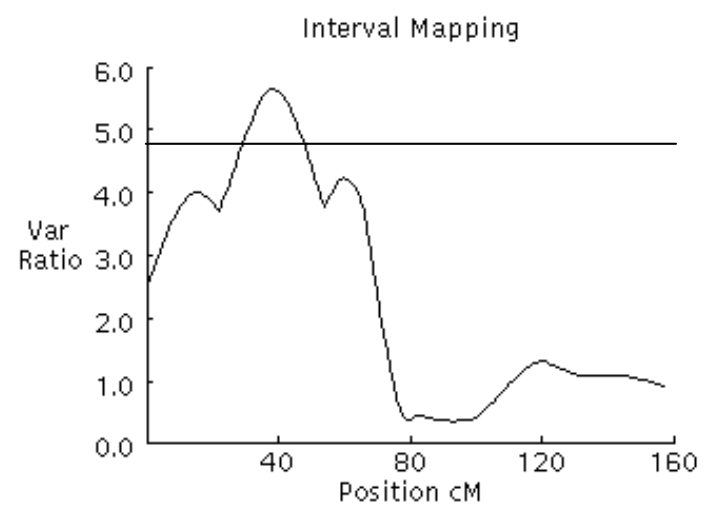

Figure 4. F-ratio curves for intramuscular fat on chromosome 8. The $\mathrm{x}$-axis indicates the relative position on the linkage map. The $y$-axis represents the F-ratio. The horizontal line indicates the 5\% chromosome-wide significance level from the permutation test.

HFABP and the melanocortin-receptor 5 (MC5R) may constitute positional candidate genes for QTL affecting IMF. On the other hand, a suggestive QTL for IMF was detected and located in the FABP4-s0073 interval (De Koning et al., 1999; Rattink et al., 2000). No QTL for IMF, however, was detected on SSC 4 in the present study.

\section{CONCLUSION}

Highly marbled meat is generally considered ideal given that it is associated with greater flavor, increased meat tenderness, and desirable cooking properties. The marbling score reflects the intramuscular fat content. IMF is one of the most economically important traits in modern pig breeding.

In this study, $\mathrm{F}_{2}$ animals from a cross between Korean native boars and Landrace sows were analyzed using an interval mapping procedure with the least squares regression method. We identified two significant and two suggestive QTL affecting body fat and IMF traits. Specifically, a QTL associated with IMF on SSC 6 strongly suggested that SSC 6 contains genes affecting IMF. The detected regions, however, should be narrowed to obtain more precise estimates of the QTL locations using additional markers. In addition, commercially relevant populations of pigs should be examined for the QTL to identify whether variants for these regions exist, which could be used for marker-assisted selection or markerassisted introgression for breeding in pigs. Further studies should also examine interactions between the QTL identified herein and other QTL.

\section{ACKNOWLEDGEMENTS}

This study was supported by the Technology Development Program for Agriculture and Forestry, 
Ministry of Agriculture and Forestry, Republic of Korea, 2-5-13 Agenda research (PJ006707) from the National Institute of Animal Science and a grant (PJ008068) from the Next Generation BioGreen 21 Program, Rural Development Administration, Republic of Korea. The authors would like to acknowledge Dr. Max F. Rothschild, US Pig Genome coordinator, for contributing fluorescent microsatellite primers.

\section{REFERENCES}

Andersson, L., C. S. Haley, H. Ellegren, S. A. Knott, M. Johansson, K. Andersson, L. Andersson-Eklund, I. Edfors-Lilja, M. Fredholm, I. Hansson, J. Hakansson and K. Lundström. 1994. Genetic mapping of quantitative trait loci for growth and fatness in pigs. Science 263:1771-1774.

De Koning, D. J., L. L. G. Janss, A. P. Rattink, P. A. M. van Oers, B. J. de Vries, M. A. M. Groenen, J. J. der Poel, P. N. de Groot, E. W. Brascamp and J. A. M. van Arendonk. 1999. Detection of quantitative trait loci for back fat thickness and intramuscular fat content in Pigs (Sus scrofa). Genetics 152:1679-1690.

Gerbens, F., D. J. de Koning, F. L. Harders, T. H. Meuwissen, L. L. Janss, M. A. Groenen, J. H. Veerkamp, J. A. Van Arendonk and M. F. te Pas. 2000. The effect of adipocyte and heart fatty acidbinding protein genes on intramuscular fat and backfat content in Meishan crossbred pigs. J. Anim. Sci. 78:552-559.

Gerbens, F., A. J. van Erp, F. L. Harders, F. J. Verburg, T. H. Meuwissen, J. H. Veerkamp and M. F. te Pas. 1999. Effect of genetic variants of the heart fatty acid-binding protein gene on intramuscular fat and performance traits in pigs. J. Anim. Sci. 77:846-852.

Green, P., K. Falls and S. Crooks. 1990. Documentation for CRIMAP, version 2.4. Washington Univ. School of Medicine, St. Louis, MO, USA.
Grindflek, E., J. Szyda, Z. Liu and S. Lien. 2001. Detection of quantitative trait loci for meat quality in a commercial slaughter pig cross. Mamm. Genome 12:299-304.

Haley, C. S., S. A. Knott and J. M. Elsen. 1994. Mapping quantitative trait loci in crosses between outbred lines using least squares. Genetics 136:1195-1207.

Knott, S. A., L. Marklund, C. S. Haley, K. Andersson, W. Davies, H. Ellegren, M. Fredholm, I. Hansson, B. Hoyheim, K. Lundstrom, M. Moller and L. Andersson. 1998. Multiple marker mapping of quantitative trait loci in a cross between outbred wild boar and large white pigs. Genetics 149:10691080.

Marklund, L., M. Johansson Moller, B. Hoyheim, W. Davies, M. Fredholm, R. K. Juneja, P. Mariani, W. Coppieters, H. Ellegren and L. Andersson. 1996. A comprehensive linkage map of the pig based on a wild pig-Large White intercross. Anim. Genet. 27:255-269.

Ovilo, C., M. Perez-Enciso, C. Barragan, A. Clop, C. Rodriguez, M. A. Oliver, M. A. Toro and J. L. Noguera. 2000. A QTL for intramuscular fat and backfat thickness is located on porcinc chromosome 6. Mamm. Genome 11:344-346.

Paszek, A. A., P. J. Wilkie, G. H. Flickinger, G. A. Rohrer, L. J. Alexander, C. W. Beattie and L. B. Schook. 1999. Interval mapping of growth in divergent swine cross. Mamm. Genome 10:117-122.

Rattink, A. P., D. J. De Koning, M. Faivre, B. Harlizius, J. A. M. van Arendonk and M. A. M. Groenen. 2000. Fine mapping and imprinting analysis for fatness trait QTLs in pigs. Mamm. Genome 11:656-661.

Rohrer, G. A., L. J. Alexander, Z. Hu, T. P. L. Smith, J. W. Keele and C. W. Beattie. 1996. A comprehensive map of the porcine genome. Genome Res. 6:371-391.

Rohrer, G. A. 2000. Identification of quantitative trait loci affecting birth characters and accumulation of back fat and weight in Meishan-White Composit resource population. J. Anim. Sci. 78:2547-2553. 